\title{
1985 to 1995: The Next Decade in Academic Librarianship, Part I
}

\author{
Allen B. Veaner \\ With a Preface by Page Ackerman
}

This article is based closely on a working paper commissioned by the Academic and Research Libraries Personnel Study Group of the Association of College and Research Libraries, a division of the American Library Association. Its purpose is to "explore the implications of the changes to be expected within the foreseeable future (1985-95) in the environment, mission, functions, and operations of academic libraries (from junior colleges to large research universities) on librarians and librarianship." " Letter of January 25, 1984, from Page Ackerman, chair of the study group, to the author.] The author has been asked to maintain a focus on working librarians, not chief administrators. Current views and forecasts about the future of academic librarianship cover a very wide spectrum, from the apathetic to the desperate and frenetic. Fortunately, calm and reasoned considerations can also be found; it is believed that these form a sound basis for future programs and actions by ACRL. Although we are passing through an era of very rapid technical change, the author has chosen to focus upon certain constants in scholarship and education. In planning for the future, the author counsels care and thoughtfulness coupled with reasonable dispatch and avoidance of promises of panacea.

\section{PREFACE}

In January 1982 ACRL established the Academic and Research Libraries Personnel Study Group to assess the adequacy of ACRL's current personnel programs and priorities, and to suggest initiatives needed to assure a suitably comprehensive program, coordinated within ALA as deemed useful. The study group consisted of representatives from the Academic Status Committee, the Chapters Council, the Continuing Education Committee, and two discussion groups (personnel administrators and staff development officers), plus three members at large including the chair.

By January 1984, the study group had concluded that, although current programs were well designed to respond to membership needs, ACRL was not well positioned to exercise effective influence or leadership in anticipating and addressing changes in academic libraries that may significantly affect the academic librarian's future contribution, status, and welfare. With board approval the study group commissioned Allen Veaner to write a working paper exploring the implications for librarians and librarianship of the changes to be expected within the next decade in the environment, mission, functions, and operations of academic libraries of all types. We also asked him to consider ACRL's appropriate role in responding to such change. Our objective was to provide

Allen B. Veaner is a library consultant, 45 Inglewood Drive, Toronto, Ontario, Canada M4T 1G9. Page Ackerman is chair of the Academic and Research Libraries Personnel Study Group of ACRL.

The author thanks the many readers who reviewed the full-length report on which this article is based. He especially wishes to thank the members of the ACRL Academic and Research Library Personnel Study Group, who contributed valuable criticism and suggestions on early drafts. He also thanks Susan Klement, his wife, who went over the paper very carefully, brought fresh views from other perspectives of librarianship, and patiently assisted with many aspects of content, style, and composition. 
ourselves with a speculative context within which we could develop useful recommendations for ACRL. We have found the working paper provocative as well as useful and hope that it will stimulate widespread discussion among academic librarians.

$\mathrm{Mr}$. Veaner's paper represents his views, not those of the study group members nor of the members of the committees and discussion groups they represent. Because the Academic Status Committee has reservations about the paper's treatment of issues directly affecting professional employment standards, responsibilities, and related questions, their comments accompany the original working paper and should ideally be read in conjunction with it. The study group hopes to approve a final draft of its report and recommendations to the ACRL Board at the 1985 Annual Conference-Page Ackerman.

\section{THE CONTEXT OF ACADEMIC LIBRARIANSHIP ${ }^{1}$ A Rapidly Evolving Context}

New theories of scholarly communication are evolving. They range widely, from the possible and probable to the fanciful and unlikely. In recent years there has developed a substantial body of "library science fiction" that has deemphasized collections, collection development, and the role of human intelligence as embodied in librarians. Leaning upon the wonders of digital communication and electronic technology, there has arisen a thesis that the whole contents of collections currently maintained by libraries-books, films, journals, videotapes, etc.-are simply "containers" for large supplies of "information" buried therein. It is as if the library is a mine or well and that by bringing in the right equipment, its contents can be conveniently tapped, extracted, or drawn off. In this scenario, academic librarians as they now exist are but keepers and custodians of the containers, or "markers and parkers" 'at best. In the words of Cronin (1983), the proponents of such theses view the librarian/information professional "as a latter-day dinosaur or brontosaurus, unable or unwilling to come to terms with a changing landscape." Cronin adds an insightful coda:

What is most revealing about these analogies is their inflexibility; invariably the projections are linear, based on fuzzy data and 'surprise-free.' And, of course, the whole point about the 'third wave' is that it is going to drench us in surprises. $^{2}$

The chimeric aspects of this dinosaur thesis ought to be self-evident: First, there is ample evidence to contradict the notion that the librarian/information professional has no capacity to adapt. Next, no matter what technological advances occur within the next decade, human beings will continue to rely upon systems of recorded knowledge that reside in collections maintained by institutions dedicated to the preservation and communication of their contents to the community of students, researchers, and scholars. Furthermore, these collections do not select or organize themselves but require specific human intervention. Nor, in the modern era, do such collections come into being as the consequence of the effort of a single person, or even a small group of persons; today's collections have an institutional dependence as never before. Regardless of nomenclature or form of material, the institutions that maintain these collections will continue to be libraries. Ultimately, it is society itself that must support the academic library as a public good.

For many reasons the responsibility for maintaining collections of instructional and research materials covering every time span, every country, every civilization, every language cannot be delegated to the private sector. The private (and some not-for-profit) sectors are driven by different motivations than the academic sector; they cannot be expected to take responsibility for the totality of human scholarly endeavor and interest. Of course the private and not-for-profit sectors effectively market a number of useful access and control systems (some developed at public expense)-systems that can provide citations, and increasingly, full text. But the idea that these systems "mine" information must be dismissed. "Information" is touted as a commodity, a concept that may be valid in the business world. 
But the information and knowledge of the academic world cannot be canned. Information and knowledge are spiritual relationships among humans, mental constructs that exist in the mind-not as marks on paper or bits on disks. ${ }^{3}$ In colleges and universities, academic librarians select and organize the materials of instruction and research, acting as vital links between collections and users. In the complex and dynamic interrelationships that occur in the process of scholarly communication, especially in the creation of new knowledge, librarians constantly demonstrate their polydimensionality: they and their collections are vehicle, wheel, axle, and linchpin; vessel, compass, sail, and rudder. This is currently the case and will likely continue to be the case for the remainder of the twentieth century, perhaps even beyond.

\section{Educating Scholars, Faculty, and Administrators, 1985 to 1995}

Because academic librarianship is a life of the mind and not a job of simply managing a warehouse of physical materials, we should always stress the intangible aspects of library service. One useful way to emphasize this idea is to promote the concept that the library is not a place but a service. Academic librarians-not the facility in which they work-ought to be conceived as the providers of the library's services, as the source of information, data, responses, answers, and intelligent dialogue. But virtually all our promotional materials promote libraries. Posters, spot advertisements on radio, $\mathrm{TV}$, or other media, and National Library Week all focus on the institution, not the professional staff, as the source of information. ${ }^{4}$ Might we profitably use a National Librarians' Week? At least academic librarians ought to devise public relations programs that focus upon the special education and subject expertise of librarians. Our clients should be urged to come not to the library collection itself but to those marvelously expert, well-educated, and highly trained intermediaries-the librarians. They are the professionals who transform the inert, dead contents of the institution into "information" - the live communication that alters the behavior of the client.

In 1982 ACRL began a three-year experiment with nine nonlibrary professional associations to promote the awareness of the potential values of bibliographic instruction (BI) in the learning process-an important and significant contribution to extending an understanding of the teaching role of academic librarians into the academic community at large. Five of these associations are members of the American Council of Learned Societies (ACLS). ${ }^{5}$ Such workshops and seminars can be of incalculable value in changing the perception of the librarian and the librarian's place in the academic process. Collaborative programs will be expensive and their returns visible only in the long term. ACRL ought to continually evaluate cooperative programs, improve them, and reach out systematically for the remaining membership of the ACLS and the membership of other, similar societies in the U.S. and Canada. ${ }^{6}$

Programs are sorely needed to make educational administrators aware of what academic librarianship is truly about. Moffett (1982) reports a series of dismal incidents from librarians and library administrators that illustrate the lack of understanding among faculty and campus administration of the role of the academic librarian. The images are familiar: librarians emerge "somewhere between secretaries and warehouse supervisors," are regarded as "technicians or bureaucrats," but not as peers or collaborators. Concerted efforts at both institutional and national levels are required to combat such damaging misperceptions. At the local level, the effectiveness of any educational campaign will depend almost entirely on the chief librarian's political skills and creativity; where those skills are lacking, there can be little hope of success. The problem of communicating adequately with educational administrators is national in scope; it deserves the same kind of aggressive campaign now being conducted with the scholarly organizations. ACRL should investigate the feasibility of organizing educational programs to communicate a better understanding of academic librarians' special responsibilities, 
knowledge, and skills. Such campaigns may be beyond the current expertise of the profession itself; likely they will entail expensive contracts with specialized firms or consultants and a continuing commitment with payoff in the distant future.

\section{Governance in Academic Libraries}

Among large libraries functional departmentation has virtually dictated hierarchical structure. Large libraries are distinguished from small in a fundamental aspect inherent in administration itself: the chief role of administration is the unequal allocation of limited resources-the decision to support Program $X$ and cease supporting Program Y. Such decisions cannot easily be reached by committee, collegial decision making, or other democratic processes. Most especially such decisions are extremely difficult to reach if they include termination of staff. In a paper dealing with educating library professionals, Battin (1982) argues that in the large research library, the idea of librarians constituting themselves as a corps of autonomous professionals (like faculty) is untenable. The faculty model of a group of loosely affiliated, autonomous colleagues governing themselves along collegial lines may work in teaching and research, maintains Battin, but cannot be implemented in the large research library.

The idea that hierarchical structures will decline in the developing "information society" is pervasive in much of the literature that deals with the future, and to some extent was a theme at the Third ACRL National Conference. ${ }^{7}$ The decline of hierarchy and its replacement with democratic styles of governance is especially appealing to employees who grew up in the comparatively affluent post-World War II era and went to college in the "permissive" 1960s. For many of them the idea of hierarchy is repugnant and unacceptable. While it is true that many libraries implemented limited "democratic" or participative forms of governance and administration beginning in the late 1960s, among very large libraries the fundamental hierarchical pattern remains with practically undiminished strength.
If hierarchy declines as a structural style, it is likely to occur first among small, highly technological industries where almost all the manufacturing is automated, and operations are run by a "college" of managers who have heavy financial stakes in the enterprise. The environment of small units-the college library, the junior college, or community college library-is suitable for a collegial, nonhierarchical style of governance and operation, especially if all production (i.e., "manufacturing") can be handled by computers, networking, or clerical staff (no manual files to maintain, little or no cataloging to do, fully automated circulation system, and stack maintenance run by clerks). This would leave a "college" of librarians to share authority and responsibility for the intellectual connection with faculty and academic programs. In such an atmosphere it would be comparatively easy for a small group of professionals to share in major programmatic and resource allocation decisions.

Of course, the issue of governance in the academic library cannot be oversimplified by postulating large and small units, with the former hierarchical and the latter collegial. Assuming that the librarian is to be "deinstitutionalized," that access to information is to be democratized via personal computers, that hierarchy might break down in some organizations and remain in others (e.g., the large research library), what governance structures can be postulated for academic librarians? Is collective bargaining the answer throughout academe? Would it be useful for ACRL to commission studies of changing organizational structures in libraries? Would the results be a spectrum of structures, varying according to library program and institutional character? Would such a study be too theoretical, inevitably behind the realities of the field?

In the final analysis, the matter of governance will be resolved at the local level (or the system level, for the large, multicampus institution). This observer suggests that the governance issue, though important, may be less weighty than the role issue for librarians. If the academic librarian's role in the institution's intellec- 
tual life can be assured, the librarian can accommodate to almost any governance style, much as faculty have. But closure on the issue of role ought to precede concerns about governance.

\section{Competition, Incentive, Commitment, and Restructuring in the Bibliographic Enterprise}

"Deregulation" is remolding U.S. business and industry through the encouragement of competition. Is there an equivalent for personnel administration in academic libraries? Within current college and university structures the answer must be no, for the library is still a campus monopoly, the Ma Bell of academe, its professional staff residing in a well-protected enclave. But new technology has the capacity to break this monopoly as faculty and students send electronic tentacles out to commercial databases and use electronic mail to communicate with expert colleagues elsewhere. The breaking of any monopoly strongly suggests opening up opportunities for competition in academic library work. Devising humane systems for fostering a competitive spirit will be a principal challenge to library administrators.

Competition can originate internally and externally. Internally, librarians can be stimulated to compete with each other, to put out their best creative, innovative efforts, to communicate and publish more, to participate fully in the profession. Externally, competition is not within the control of librarians but originates from the information services offered by the private sector, where the initially harmless barking at heels by small dogs has now become the howling of hungry wolves.

In business and industry one of the most attractive ways of stimulating commitment is the provision of opportunities for young managers and executives just beginning their careers to buy into the firm as part owners. To some extent such an arrangement is available in the professoriate, where tenured faculty in an academic department control an academic program within the university or college's basic charter; this in fact is what a college really is-a cluster of intellectual experts who control educational resources. Except for the library-college movement that flourished in only a few institutions, this style of collective "ownership" and commitment has never developed in the academic library. The middle-sized to very large academic libraries remain hierarchical bureaucracies whose organizational structures have a tendency to foster overattention to narrow specialization and comparative inflexibility. Only in the smaller academic libraries is the collegial pattern practical. Can a method be developed to overcome bureaucratic inertia? Is it possible to restructure larger libraries so that academic librarians can, like their counterparts in business and industry, build institutional commitments that result in self-motivated continuing education, self-motivated attention to development of time- and money-saving schemes, self-motivated outreach to clientele? In the large library, the question might be asked whether departmentation, a pattern now half a century old, has not outlived its usefulness and has become counterproductive.

Many distinguished librarians and educators have spoken of recasting the profession to stress it as a unity of human (i.e., intellectual) and physical resources, plus a communication system (e.g., bibliographic traditions and networks) dedicated to the whole complex information processing enterprise. It is vital that such ideas percolate down to the rank and file of academic librarians, not simply remain as abstract concepts in the minds or offices of administrations. Abell (1982) has proposed shifting academic library organization from its present function-oriented structure to one directly related to broad disciplinary groupings. ${ }^{8}$

Such a proposal can be implemented in virtually any size academic library and has the merit of moving away from the currently popular "aggregate of independent functions" structure to something more integrated, more academic. ACRL can hardly be expected to postulate idealized (and probably unworkable) structures for every size and type of academic library, but Abell's proposal to restructure the aca- 
demic library is worth pursuing as a theme for a future national conference: "Restructuring the Academic Library in an Era of Rapid Change." This would fit in nicely with Battin's urgings for a restructuring of the entire university apparatus. ${ }^{9}$ The distinct structural needs of medium-sized universities, colleges, and community colleges could emerge from conference dialogue and position papers prepared in advance. Regional workshops could assist in spreading the restructuring ideas proposed by Abell (1982) and others, and in developing alternative concepts.

Returning to the matter of incentives, one can summarize the issue by asking whether a nonprofit institution can adopt useful profit-sharing techniques so that its members can get "a piece of the action." Can the academic library devise incentive systems, so successful in industry, to stimulate productivity and innovation ? $^{10}$

On the faculty side, Koerner (1977) deplores the professor's preference for writing a scholarly book for a "tiny readership" to "creating a technology-based curriculum for large groups of undergraduates." In respect to incentives, he goes on:

Private industry learned long ago that incentive and bonus systems built around increased efficiency, cost-cutting ideas, and improved service, can pay for themselves many times over. Comparable systems in higher education are nonexistent, but the possibility of creating them deserves examination. ${ }^{11}$

The creation of incentives for excellence in the academic library is a major challenge. Lack of adequate institutional incentives has persuaded some librarians to flee to the for-profit sector or go into business for themselves as information brokers or purveyors of other information-related products or services.

There are also the questions whether professionals can be motivated to adopt a less reactive stance to the bureaucratic environment, and whether or not the structure itself can eventually be changed. In large organizations, ponderous bureaucracy encourages proactive behavior less than a "company ownership" structure where survival depends upon productivity. Although the environments are not precisely comparable, it may be noted that special libraries in business and industry are claimed to be more service oriented than are academic units-because the survival of the company library is perceived to depend heavily upon immediacy and quality of service. Company survival, too, depending upon the size of the company, might be perceived as at least partially a function of the quality of library service. Can any of the "survivalist" attitudes from special librarianship be transferred to the academic environment? Can a structure be devised that librarians can "buy into" or "own" to help develop incentives to excellence?

\section{"De-Recruitment"}

It is no surprise that the academic library, like any other complex enterprise, has problem personnel. The presence of unproductive people cannot be attributed to single causes. In an acerbic review, Yerburgh (1983) rails against recruitment practices that bring weak people into the profession. ${ }^{12} \mathrm{He}$ attributes many of the professional's personnel deficiencies to a lack of both "enlightened leadership and gifted members of the rank-and-file."

Every manager cherishes the fantasy of administering a library unfettered by those who consume institutional dollars but do not produce. Many of these are the "lifers" in the educational bureaucracy, whom Yerburgh calls the "little gray men and women." They are the people who belong to no professional associations, attend no conferences, do no committee work, write no papers, analyze no problems. They are the people who have found a "parking spot," who can be counted on to come in a bit late and leave a little early, and not miss any coffee break. Forced by institutional structures to rely on attrition, many managers are reduced to coping with the "lifers" by keeping in their desk drawers a dated list of upcoming retirements as an aid to personnel planning. Is there a better way?

Librarians weed books unhesitatingly. Pruning staff is undertaken with less enthusiasm. The profession has no method in place for "de-recruitment" or outplacement. How does an institution rid itself of 
deadwood? Can humane systems be devised to identify and deal with staff members who are unproductive, incapable, or unwilling to retrain?

Every institution has a social obligation to long-term employees; such obligations may be secured by contract, law, or custom. The principal challenge is financial, as administration would have to "buy off" such persons through attractive early retirement schemes, and the money for that competes with the budget for productive work. Because the profession has done little to cope with this type of problem, it is left to the administrator to resolve-with sometimes grudging assistance from institutional attorneys and personnel managers. It would be very difficult, perhaps impossible, for ACRL to enter this sensitive and difficult area; the best hopes lie in encouraging member institutions to uplift their hiring standards and not hire weak candidates, and in urging the schools to raise their admission and retention standards.

\section{Fragmentation and Restructuring}

In the light of so much fragmentation in the profession itself, one might ask whether ACRL's current organizational structure is suitable to the achievement of its mission. In many ways, ACRL represents the ultimate in the professional fragmentation so characteristic of librarianship. The ALA Handbook of Organization for 1983/84 reveals that ACRL is comprised of nearly 250 separately identifiable units.

Nearly all the major library associations in North America are similarly divided into a seemingly infinite multiplicity of interest groups. Perhaps this atomization merely reflects the general academic fragmentation that has characterized research since the nineteenth century. Internally, we debate the profession's inability to speak with one voice, yet the responsible forces may be the same ones that divide the entire academic establishment into so many parts. Institutional structures, such as hierarchy and departmentation in the larger libraries, assist the process to the point where isolationism can develop to ridiculous extremes. ${ }^{13}$
Automation has undoubtedly contributed very positively and powerfully to the breakdown of artificial barriers unintentionally constructed through departmentation. Personnel exchanges, rotations, dual assignments, and other techniques have also helped to ameliorate the consequences of fragmentation. Other artificial walls of false elitism have been built upon the layered rankings of institutional prestige. The facts of high prestige and high institutional quality should not inhibit the free and ready interchange of ideas and collegiality at the national level. Continuation of the regional ACRL conferences is a strong integrating tool on behalf of the membership, a device that promotes desirable exchange of ideas from all types and sizes of academic libraries.

Much of ACRL's structure perforce mimics the complexity of the parent organization. Given the rapidly developing technologies supportive of institutional restructuring, the growing trends toward decentralization in government and society at large, and the evolution of new designs for work itself, is it not appropriate for ACRL to review its own structure?

\section{Low Visibility on Campus}

The low visibility of the academic librarian's role in education may be attributable in part to traditions of passive, reactive behavior or, in part, to the image of the academic librarian as keeper or custodian. Leaders in academic librarianship have been successfully challenging this tradition in recent years. But, as with a giant oil tanker underway at full speed, there is much inertia to overcome; a huge "establishment" like traditional librarianship does not shift direction instantaneously. Academic library leaders require time to plan and implement initiatives and those in the field need reasonable time and opportunity to adapt. Yet the changes wrought by the computerization of conventional bibliographic operations are, in all probability, the advance guard of even more comprehensive change.

Who are the librarians? A university president, Ilchman (1982), asserts that we have a fuzzy image. The fact that even so critical a document as A Nation at Risk 
failed to mention the library's role in ameliorating serious education deficiencies in the U.S. is very telling. But how can we explain to faculty and administrators what academic librarians do? For years we have described librarianship's professional and clerical needs to personnel managers and recruitment officers by focusing upon the visible operations that go on in libraries. We have learned to excel in writing position descriptions and job descriptions. Unfortunately, when communicated to the outside world, these descriptive models become a trap in which we ourselves are caught. A focus upon visible operations denies the fundamental academic character of the librarian's work! Precisely because academic librarianship deals so much with concepts and abstract constructs, we, like faculty, depend more upon invisible ideas and words than coarse, descriptive pictures to convey our work. Descriptions of the manifold activities administered by librarians can only explain the numerous visible operations largely carried out by support staff-and it is this visible work that confuses the client's mind on what we professionals actually do. Because librarians' true work is as invisible (and indivisible) as the work of faculty, we, like they, need similar supplementary mechanisms to gain visibility. Among those mechanisms are the following:

- high quality scholarly publications

- broad involvement in academic planning and institutional governance

- appropriate participation in the work of learned societies and professional organizations

- collaboration with faculty as expert intermediaries in the research process

- pervasive programs of bibliographic instruction

\section{Faculty Status}

Librarians' long-standing concern for their academic status culminated with the award of faculty status in many land grant universities in recent decades, although there has been little progress among private universities and a lack of enthusiasm among the administrators of very large research libraries. English (1983) thinks that the pressure for faculty status has not only "run its course" but may have begun to move into reverse. ${ }^{14} \mathrm{~A}$ current paper by English (1984) suggests that university administrators see no advantage in librarians possessing faculty status; further, English reveals, administrators expect little of librarians in the way of academic achievement. ${ }^{15}$

Nearly all respondents to the author's informal survey conducted for this study pressed for equal status with faculty. One respondent suggested that faculty status was "inappropriate" for academic librarians. This same respondent stated that teaching and research faculty simply do not recognize librarians as their peers and further observed that librarians were unwilling to assume equivalent research, publication, and related responsibilities. Massman (1972) who has studied the subject exhaustively repeatedly cites the point that librarians who expect faculty status must be prepared to meet equivalent criteria for evaluation and advancement. ${ }^{16}$ The dilemma, of course, is that while research and teaching faculty can conveniently maintain highly flexible schedules, often with a quarter or semester free from teaching, librarians are normally confined to forty-hour weeks at their work stations, whether in reference, cataloging, or collection development.

The solution to the academic librarians' status problem is not likely to be reached in the bureaucratic arena or on the floor of the academic senate. It is doubtful also whether librarians will gain faculty status via any system of ACRL sanctions or via the application of ACRL standards to academic institutions. It is conceivable that some progress might be made by political alliances with faculty in the collective bargaining arena, but whether the benefits gained would result in an enduring social and intellectual equity is questionable. Once "used" to gain a political objective, librarians might still find themselves relegated to second-class citizenship in the academic community.

It appears to this observer that one key to the improvement of librarians' academic status may be further off-loading of their production work onto support staff. For librarians to reach genuine parity with 
faculty, it is necessary to get librarians completely out of the "manufacturing" business. ${ }^{17}$ Technical service librarians can then join public service librarians in a united professional cadre capable of complementing faculty through several invaluable roles: research colleague, bibliographic expert, information system manager, and information system use instructor. On the other hand, should the Lancastrian model of the "paperless" society and the "de-institutionalized" library come to pass, some librarians might find themselves working as free-lance entrepreneurs-in which case the faculty model could become irrelevant.

\section{The Lawyer/Physician Comparison as Related to Professionalism and Faculty Status}

The argument against faculty status in academic librarianship sometimes finds an amicus curiae in the view that librarianship is not a profession. The combined argument reaches out beyond the professoriate to other professions, and even to the trades, and goes something like this: Lawyers do not teach their clients to handle their own cases; physicians do not teach their patients how to cure their diseases or how to perform successful surgery; mechanics do not teach automobile owners how to overhaul their cars. But librarians are always sharing their expertise-with faculty, students, and the general public. Not only do they share their knowledge freely; they actually give it away at no charge, a practice long regarded as a social good.

It is then suggested that librarians, by teaching their clients, ultimately work their way out of their jobs, i.e., destroy their jobs by showing their clients how to function independently. (No one directs such criticisms to teachers or faculty; no one says that through the act of instruction, faculty are working their way out of their jobs.) Yet this view ignores the point that one of the academic librarian's key responsibilities is teaching. This view also presupposes that knowledge is finite-even though all recognize that information and knowledge constantly grow, that every stage of development, new populations need information-from elementary facts to the most technical theories of science. "New" information is constantly derived from "old" knowledge; even misinformation itself is a legitimate subject. It is the very infinity, the "never-emptiness" of information and knowledge, which makes librarianship one of the world's most exciting professions. If "information" is a well, it is one that never goes dry; it dispenses an infinite variety of refreshment. No, the information profession cannot destroy itself through sharing; if anything the teaching/instructional function serves to enhance the status and essentiality of those who perform it.

The lawyer/physician comparison is weak at best and should not play a role in the issues of professionalism of faculty status. First of all, clients only go to lawyers and physicians in cases of pressing immediate need, often where life, career, family, or financial stability are threatened. Like plumbers and roofers, lawyers and physicians deal mostly with emergencies. Not so with the academic librarian who ideally is the constant partner of student, faculty, and researcher. Additionally, legal and medical professionals typically work with a client on one specific problem, and when work on that problem is completed (or the client runs out of resources), the transaction is terminated. Yet by definition the scope of the academic librarian's work-like that of the facultyis unlimited, restrained only by the capacity, curiosity, ingenuity, and motivation of the student or colleague; similarly, the time duration of the librarian's work is perpetual. The life of the mind, as embodied in academic librarianship, is not constrained by the artificial barriers of discipline or schedule that delimit the work of attorneys and physicians.

\section{SOME FUNDAMENTAL INSTITUTIONAL CHANGES From Overhead to Transaction Accounting}

Until recently almost every library service was supplied "free" to the user, paid for by institutional overhead. For the financial planners in academe, "information" has indeed been a refractory material-inexact, inchoate, individually 
tailored to each user, highly resistant to attempts at quantification. Despite many efforts, it has not yet been possible to disaggregate the costs of information services in a way that is politically acceptable in an academic institution. ${ }^{18}$ This impossibility is possibly one of the reasons why the overhead pattern of supporting library service has persisted so long. But another reason is that much of the actual work required to access the library's resources has had to come from the users, who already "pay" for this activity by investing their own time and energy. Dedicated public service librarians may wish to challenge that point, but consider the following that users have until recently always had to do, unaided by any external support system, save their own time and energy:

- Travel to the library, a resource that is inaccessible without the user's physical presence.

- Manually search catalogs, indexes, and other access tools.

- Manually fetch and return materials.

- Fill out charge slips by hand.

- Read, digest, abstract, sort, disregard, copy, or otherwise process the materials.

- Negotiate time-consuming procedures for materials not on the shelf.

- Wait a comparatively long time for delivery of interlibrary loan materials.

To be sure, some faculty have grants generous enough to pay graduate students or teaching assistants to do all or part of the above, and some libraries offer expedited delivery of materials direct to faculty offices. But the menial jobs nevertheless must be done and there is a cost associated with their performance. With automated systems, many of the costs formerly "absorbed" by the user are now transferred to systems and apparatuses which demand "real" dollars in payment.

The idea of paying for any kind of library service probably had its origin in the establishment of photoduplication services, the first modern technological device to multiply or amplify scholarly effort. Both photoduplication and computer services, whether in-house or external, require payments that are not marginal but substantially and significantly incremental; these services lay claim on resources that, if not allocated by some pricing and cost recovery mechanism, will be consumed without limit and reduce other expected services, e.g., the provision of reference assistance and the purchase of library materials. It is this resource consumption aspect, suddenly grown to a very large scale with photocopying and computer systems, which has swung the library economy towards transaction accounting in place of the simple overhead, lump sum model. This shift is direct and incontrovertible evidence of the growth of an "information economy" right in the academic environment itself.

Proprietary interests in communication and publishing-whose representatives typically identify themselves as "stakeholders" in such discussions-were the first to articulate this economic model. They staked their claims while many librarians continued to maintain the "free" library service concepts "programmed" into their education. It is because of their proprietary views that the Copyright Clearance Center was established and it is they who continually stress that information is not free. Nowadays one reads of schemes to have microprocessors scan document identification codes, debit a user's account and credit an owner's account via electronic funds transfer. An interesting consequence of the extremely rapid development of electronic mail, personal computers, and such networks services as BRS/After Dark and DIALOG's Knowledge Index is that the acrimonious "fee-vs-free" debate has quieted down somewhat. There is no longer any debate about paying royalties for the use of information; information services of all kinds must be paid for. It is only a matter of deciding how to finance them and how to assure reasonable access to the less affluent and the less literate.

Where there does remain debate is how far computerized information technology will reach into the "information marketplace" to seek profit. One can draw a parallel with microform publishing, in which the academic community has half a century of experience. There the commercial forces tended to select the popular, high- 
profit items as candidates for microfilming, leaving vast quantities of profitless "research materials" unfilmed, or consigning responsibility for the "bottom of the barrel" to underfunded academic consortia or individual libraries. Should the commercial interests behave similarly with electronically representable information (and there is little reason to suppose that they would do otherwise), libraries could again be left holding the responsibility for access to lesser-used materials but, as with microform publishing, without the funds to carry out the programs adequately. In the end there could be a serious reduction in society's capacity to provide access to scholarly materials. Some have even expressed fears that publicly supported access to scholarly resources might ultimately disappear. ${ }^{19}$

This evolving shift of the academic library's "information economy" from an overhead to a transaction basis merits attention, possibly from the ACRL Ad Hoc Task Force on Research Needs of Academic/Research Libraries. ACRL members from the large research libraries can count on the Association of Research Libraries to defend their interests in this area, but within ACRL itself there appears to be no specific mechanism to deal with this matter on behalf of smaller university, college, and community college libraries. However, in the area of bibliographic instruction, ACRL recently began to work with certain ACLS member societies, and in this related area of mutual concern there may be room for further collaboration.

We can ask another question relating to financing academic library services: is it possible to expand (or contract) library or library-like services incrementally, in accordance with market demand? Financing an academic information service infrastructure on a pay-as-you-go basis would distribute the financial burden throughout all academic departments. If such a scheme could be implemented, light users might press for release from financial responsibility for providing library and information products and services they do not "use" much at the expense of placing unconscionable burdens upon heavy li- brary users-such as students and scholars in the humanities. However, in reality, the light users (e.g., science departments) would not reduce their cash outflow. Those who claim they "use" the library less than the humanities and therefore should "pay" less are referring to the conventional library. The sciences would actually face substantial increases in the cost of acquiring information because of unavoidable access to databases and other electronic information products and services. Such access would also incur increased telecommunications costs, and all fees paid would add up to an enormous cash outflow to the commercial sector. Thus, although it is likely that no one will get a "free ride" in the electronic library, neither will it be the case that a discipline will be able to function without such access. If some library or information services functioned on a metered basis, academic librarians would find excellent opportunities to apply their technical and financial expertise in advising academic departments on how to obtain the best value for the dollar, whatever the product or service-a function that exactly parallels what academic librarians now do with collection development. In such a context academic librarians would be needed more than ever.

\section{Impact of Marketing Information Directly to End User}

Vendors' direct marketing to end users, coupled with electronic publishing, could result in gradual decentralization of library holdings, especially if certain "holdings" may have to be redefined. Also, if electronically produced publications are "distributed," either in electronic form or in hard copy, and subject to online annotation, revision, and change, a document no longer exists as a fixed corpus. Under these conditions what will happen to conventional bibliographic control? What will be the role of a cataloger? Is it reasonable to suppose that the protocols for online publication will include "self-cataloging" features-perhaps prompted online via expert systems? Will catalogers be needed at all?

Direct marketing of database search ser- 
vices to the end user is but an extension of a long-established pattern in educational publishing, a pattern that has its roots in the marketing of textbooks and microform publications for schools and colleges. Historically, in both instances publishers typically bypassed librarians and applied their sales pressures directly to the end users, the faculty, who in turn were expected to influence bookstore or library purchase decisions. Similar pressures on campus authorities might persuade them to divert institutional funds from libraries to commercial information services.

Currently, an independent end user faces (1) formidable technical difficulties searching databases and (2) severe financial penalties for inexperience and incompetence. There are probably over 2,000 databases now available and the protocols for searching them vary considerably, despite the pressures for normalization imposed by DIALOG and BRS/After Dark. Popular literature often has physicians and lawyers bent over terminals directly accessing information vital to their concerns. In fact, it is far more likely today that these professionals will delegate such tasks to their support staff-medical secretaries, legal paraprofessionals, librarians. Librarians who search are well aware that regular-perhaps daily-experience is required to maintain expertise and keep up with system changes. It remains to be seen whether end users will acquire the expertise to do their own searching effectively and economically. Stirling's dictum that "seldom readers are slow readers" applies a fortiori to database interaction. ${ }^{20}$

White (1983) has raised a basic, practical objection to the whole concept of searching by end users:

.... we are still wedded to the forlorn and injudicious hope that somehow we must allow the researcher to maintain direct contact with the publications in his field. Forlorn because there is little evidence that he is either interested or competent in doing so. Injudicious because the best hope for this profession and its practitioners, be they called librarians, information officers, or documentalists, is that of assuming the crucial role of information intermediary between the researcher and his literature. ${ }^{21}$

Decision makers and researchers, White maintains, are not looking for more documents but for analysis: "[T] hey want to know if they [the documents] contain anything germane to the solution of their present problem." White concludes that it is a myth that end users want to do their own searching. He obviously would agree that in colleges and universities responsibility for this task is best delegated to the academic librarian. White's conclusion is undoubtedly valid at this time, and it seems unlikely that librarians are in immediate danger of losing their gatekeeping role. However, challenge is ever present: the National Federation of Abstracting and Information Services (NFAIS) has just announced EASYNET, "a new service which will make online database searching possible for the untrained end user, in libraries, offices, or campus, and at home via personal computers." ${ }^{\prime 22}$ The technical and marketing forces exemplified by the NFAIS program will certainly be tested and their outcomes worth watching.

In the matter of direct database access by the end user, it may be risky to extrapolate current cost and complexity conditions linearly. Technical devices and software are changing so rapidly that it would be unwise to ignore the potential of direct marketing. When digital communication networks replace voice grade facilities, telecommunication costs might indeed come down. When self-instructional "expert systems" are loaded into personal microcomputers far more powerful than those we have today, database searching might become much easier. Finally, one needs to face the fact that what is "difficult" for today's "seldom readers" might seem fairly simple to tomorrow's students who are growing up with terminal keyboards in their laps. Direct access by the end user and its potential risk to the academic librarian's intermediary role are areas where ACRL ought to post a "technology watch.'

\section{The Information Budget}

Future interinstitutional cooperation will not be based on noblesse oblige; courtesies that can be afforded when transaction volume is low tend to be discontinued when demand rises. Just as we pay ven- 
dors for new electronic servicestelephone access charges, connect time, lines printed, bits transmitted-and pay each other for interlibrary loan transactions, so will we probably exact charges from each other for all information-related transactions. Such a situation is not new in any sense; internally, universities have done this for years by a system of recharges for services rendered by facilities management agencies (systems office, controller's office, paint shop, etc.). The difference will be in applying the recharge system to a resource that has, by tradition, been "free." Academic departments will probably have "information budgets," not unlike their budgets for telephone service, new office furniture, repainting of quarters, and the like.

What will be the impact upon the academic librarian? An immediate suggestion is that librarians will also be responsible for these "information budgets," which will include not only their time but all the machine and electronic resources at their command. Because librarians will be the management experts in information systems, they will continue to develop and apply their professional expertise by advising faculty, researchers, and students on the administration of information budgets. In fact, one can expect to find academic departments delegating their "information budgets" to librarians, much as they have, in effect, already done with the library materials budget for a generation. As with library materials, these "information budgets" will contain real moneynot "funny money," and librarians will be held closely accountable for their effective management.

\section{THE END OF LIBRARIES?}

We rightfully remind ourselves that the computer is merely a tool. But the adverb "merely" may fail to convey the distinguishing character of the device. Many earlier tools and techniques were but linear extensions of a scholar's personal capacities or, more frequently, convenient extensions of physical rather than intellectual abilities. The telephone eliminated distance as a consideration in verbal communication; the photocopier replaced slow, cumbersome note-taking. But because the computer, to use Doug Engelbart's expression, "augments human intellect," its impact is nonlinear.

The idea of a nonlinear tool is amplified in an extraordinary and provocative volume, The End of Libraries, by James Thompson, chief librarian of the University of Reading (UK). ${ }^{23}$ In his book Thompson integrates the past, present, and future of academic libraries, portraying a picture of rapid, fundamental change. He correctly characterizes computer technology not as simply "another tool" but as a "preemptive technology," one that inevitably supersedes its predecessors, one that will make it impossible for libraries to continue as they have in the past.

In regard to the current argot, "user friendliness," the electronic medium has been characterized as not "user friendly." But is the modern academic library user friendly? Finding one's way about a major research library, especially its bibliographic control apparatus, is a formidable challenge; learning to use a terminal for a variety of applications might indeed prove much more pleasant. Line intimates that users might desert libraries for terminals "which may have their limitations but may also have fewer user-hostile elements. ${ }^{\prime 24}$

Those of us who have worked our entire professional careers in academic libraries of any size cannot really speak to the issue of "user friendliness." We have been spoiled by experience, education, and ready access to collections; we can take for granted an understanding of a very complex bibliographic apparatus. What of the less fortunate? From their viewpoint, libraries as currently organized and administered are perceived as mysterious, unresponsive, ponderous bureaucracies, obstacles to the whole information process. To paraphrase Thompson, the problem for ordinary users is that libraries, in an absolute sense, can never be convenient. ${ }^{25}$ Mysteriousness and inconvenience, once the hallmarks of the computer, have been almost completely eliminated; today a computer commands about as much notice as a bicycle. Computers and software are gradually giving users 
greater and greater power to cut through bureaucracy, formality, and red tape, to extract what they want from data files and information systems-but at a price.

Additional impetus to change will come from library users, especially new faculty and new students who will bring considerable computer sophistication and a lack of tolerance for the inconvenience of traditional libraries. It is up to academic librarians to perceive these changes in users' attitudes and expectations while they are in their formative stages-before they have coalesced into political forces that can damage the library and its interpreters. Academic librarians need to find ways to seize the initiative, to lead these changes, and not simply be dragged about by them.

Thompson's views, while stimulating and valuable, convey a certain unjustifiable panic in their tone, almost as though traditional academic librarianship were about to collapse in an instant. The cautions noted by Bell (1973), Cronin (1983), and De Gennaro (1984) are all worth bearing in mind when we hear about the "end" of libraries. But a special value of Thompson's analysis is his conclusion, which vigorously stresses one of the academic librarian's most important responsibilities, viz., to organize information, a talent not always appreciated by computer specialists, some of whom have very little experience beyond the purely technical. ${ }^{26}$ This responsibility remains, no matter what form the academic library of the future takes. So does the librarian's role as link and catalyst in scholarly communication.

\section{POSSIBLE/PROBABLE FUTURES A Shift from "Make" to "Buy"}

New technology and continuing budget crises are gradually forcing academic librarians to come to grips with "make or buy" decisions, a choice that hardly existed before computers brought about a certain degree of "industrialization" to bibliographic processing. We can no longer afford to manufacture what is available ready-made. Lancaster (1982) forecasts a rapid dwindling of technical services, because "electronic sources do not need to be selected, acquired, cataloged (at least by individual libraries), prepared for the shelf or bound. ${ }^{\prime 27}$ Brownrigg (1984) suggests that in the upcoming electronic era, cataloging responsibility will shift from the buyer to the publisher who will use it as a valuable marketing and promotional tool. The present author (1982, 1984) has suggested that technology be employed to dismantle massive technical services operations in order to redeploy resources. Aveney (1984) points out that full automation really means that the acquisitions department simply disappears, and whatever is left of the cataloging department works in museum fashion with artifacts, viz., rare books. Neil (1980) is worth quoting:

What will be different is the behind-the-scenes activity. For one thing, cataloging, its golden age passing a hundred years after Cutter said it had, will have disappeared from the worksroom [sic], replaced by a small computer to store the library's records and a terminal to access the central shared cataloging system. ${ }^{28}$

The mental and intellectual capacities of academic librarians have become strained, exhausted, and worn out prematurely by the unconscionable manufacturing burdens of bibliographic housekeeping work. Thus far we have tried, with mixed success, to use automation largely to relieve ourselves of this arduous work. More vigorous efforts to buy bibliographic products and services in preference to in-house manufacture can help academic librarians redirect their energies into other bibliographically oriented programs and services, for which technical services form only the infrastructure. This removal of production work from librarians is analogous to the removal or reduction of manufacturing work in industry and represents a kind of in-house move to an information economy. ${ }^{29}$

\section{Altered Staffing Patterns}

In the 1985-95 decade we may expect to see:

- Fewer catalogers; possibly none in junior, community, and small colleges, as out-of-the-ordinary cataloging will be done by contract with regional or subject centers where clients' materials will be cataloged from electronically transmitted facsimile copies. Even the bulk of a university library's cataloging may be 
bought from a contractor or consortium, such as the Research Libraries Group.

- Fewer clerks, as more academic library routines, e.g., circulation and acquisition, under continuing fiscal pressures, fall into a few well-defined, nationwide standard systems implemented with vendors' standard software packages, i.e., turnkey systems.

- Reduced interlibrary loan staff as commercial document delivery systems, e.g., University Microfilms' UMI Article Clearinghouse, gain popularity and deliver materials directly to the user.

- Shift of some librarians to the computer center, or combined library/computer center, for work on information systems design.

The broad and general removal of production/manufacturing work from academic librarians is the most important change and the most valuable opportunity now before the ACRL community. All production aspects of ordering, receiving, checking in, and cataloging should be offloaded to support staff, with a few librarians (or very senior support staff) to manage those operations. The effectiveness of such off-loading will depend on how successfully academic librarians (especially those in positions of leadership) adopt national bibliographic standards and accept contributed cataloging with little or no change. If electronic publishing expands as forecast, it may be possible to realize some further net reduction in production/ manufacturing work throughout the library, and a dramatic shift in staffing. (This does not mean any net reduction in total library staffing, but rather a reallocation of existing human resources.)

\section{Changing Attitudes and Policies toward Standards and Their Economic Impact}

Despite much pious talk, standards have been more ignored than observed by academic librarians. Historically, the greatest breaches of standards have occurred in cataloging, the most expensive service in medium-sized and large academic libraries. Pleading with library administrators to bring an end to expensive and continuing upheaval, Avram (1983) has enumerated some of the more egregious examples and consequences of lack of standardization. Academic libraries can no longer afford the severe financial penalties imposed by failure to observe standards. In the 1985-95 decade financial pressures will likely force directors and other managers to affirm that it is better to have records that are uniform and cheap, even if imperfect, for they will be aiming to reinvest/reallocate resources into new information systems that will supersede older style bibliographic control systems. In the 1985-95 decade, standardization, always a matter of economic necessity, will likely become universally acknowledged as a keystone of effective library administration.

ACRL can play a significant advocacy role in the drive for the further development and implementation of standards in the field. The role of standards also ought to be emphasized heavily in the curricula of graduate programs of education for library and information science. Using workshops and institutes offered by appropriate organizations, e.g., the National Information Standards Organization (Z39), and the various standards committees of other ALA divisions (and related nonlibrary organizations, e.g., AFIPS), ACRL can help educate and reeducate library managers to the vital role of standards in the library economy.

National library leaders will continue to stress the economic advantages of standards. Indeed, it may be expected that administrators, pressed hard by continuing budget cuts, will soon view strict adherence to standards as an important fiscal control device. It is they, not the technical staff, who must control the costly programs for revising AACR, MARC, and LSH. Here is what Avram told directors of the Association of Research Libraries (ARL) at the fall 1983 ARL meeting:

There has been an occasional voice in favor of AACR3. A larger group is calling for a complete overhaul of LC subject headings. LC is willing to consider making changes that are possible within the general framework-and we are currently working to this end. But any major revision of any of these standards would impact the entire library community, nationally and internationally, and would cost countless millions of dollars. What would become of the millions of records we already have in machine-readable form? ? $^{\prime 30}$ 
With the return of decentralized local processing-now possible through cheap, distributed computing - there is some risk that the era of individually tailored cataloging might return. Demands for new library services and competitive challenges (for money) from other academic programs in colleges and universities ought to act as a brake on this temptation. It would be a tragedy if the decades of progress in bibliographic standardization were to be undone by unrestrained local modification of nationally distributed cataloging copy.

\section{Changing Attitude toward Management of Institutional Resources}

Collection development librarians were the first to be keenly aware that their work resulted in cash outflow other than their own salaries: they have long been held strictly accountable for book budgets. Yet in other areas librarians have hardly been held to financial accountability and the rather antiquated view that resources are obtained by turning a tap remains embarrassingly prevalent. In the 1985-95 decade it may be expected that all academic librarians will receive resource budgets managed by a master-fund accounting system; librarians' budgets will be updated daily and reports presented on their microcomputers as well as on microcomputer displays observed by higher management levels. All academic librarians will be held accountable for the effective, economical use of their assigned resources. For all computer-based systems, resource consumption will be tracked on a transaction basis for all employees (including support staff and student employees); tracking will include librarians' access to bibliographic utilities or other networks, and interlibrarian and interinstitutional electronic mail. The effectiveness of librarians' resource management will be reviewed as part of their performance appraisal.

\section{Managers' Software}

Specialized management software is currently being marketed for high-level executives in business and industry. This software enables executives to obtain management information directly instead of (1) relying on hit-or-miss reporting by staff officers in the organization or (2) reading batch printouts with data too old for valid decision making. Using such software, tomorrow's library managers will most likely obtain the data required for rapid decision making and long-range planning directly from a console. Certainly the academic library's top administrators will have such software.

\section{Role for Robots and Artificial Intelligence?}

Friday, April 13, 1984, marked the opening of the First International Personal Robot Congress, held at Albuquerque, New Mexico. The conference, endorsed by the British Robot Society, the Robot Institute of America, and the Robotics Society of America, included educational applications. Are there potential library applications? Supposing the videodisk, satellite transmission, and wireless lap computers do become the keys to the library of the future $?^{31}$ What of the past? Must the management of our retrospective collections forever remain labor-intensive work unrelieved by mechanical assistance? ACRL and LITA might collaborate to encourage the development of robotic devices for stack management and for the efficient, rapid conversion of selected inkprint collections to digital form.

Regarding artificial intelligence (AI) and the development of expert systems, Clarke and Cronin (1983) report a disturbing lack of interest in library applications. Feigenbaum (1983) devoted a few pages of his book, The Fifth Generation, to the concept of an "intelligent library," and proposed the establishment of a National Center for Knowledge Technology. ${ }^{32}$ Yet two things are evident from Feigenbaum's book: (1) the construction of expert systems requires an inordinately high investment of time by some very expensive people, and (2) the systems function best with problems of a deterministic character.

Now, the fluidity and flexibility of human learning and the responsiveness characteristic of librarian-user interaction are precisely the strengths of natural intelligence, the librarian's most vital ability. Not everyone thinks the computer can 
match the human brain's remarkable creative powers. Hofstadter essentially dismisses the idea that intelligence can be mechanized or arise from inert, inanimate devices. ${ }^{33}$ Although AI remains a developing and controversial field, within the tenyear span of this report academic librarians need not fear that their duties will suddenly be taken over by some HAL-like computer. But since the strength of $\mathrm{AI}$ in its current state lies in dealing with events of very high predictability, AI might be a potent tool in area where we try to impose algorithms, e.g, AACR. The successful development of expert systems to cope with cataloging codes could have an attractive payoff if still more cataloging could be delegated to support staff.

With the possible exception of the LITA Ad Hoc Committee on Emerging Technologies, there appears to be no ALA unit specifically addressing the potential of AI. ACRL ought to post a systematic watch on AI, in collaboration with LITA, ASIS, and other appropriate organizations.

\section{Broadened Bibliographic Access}

Wide access to computerized bibliographic data and full text have the capacity to exercise a powerful leveling effect in academe. Computerized information systems, especially those services marketed directly by commercial vendors to the end users, may "demystify" arcane aspects of bibliographic and information retrieval. Specialist faculty, graduate students and teaching assistants, and academic librarians in the elite institutions may no longer constitute a premier, invisible academy of gatekeepers or pioneers at the frontiers of knowledge and research. Possibly electronic information systems can democratize aspects of research, bringing opportunity to the academic stars of lesser galaxies. But without ready cash for entry and access this opportunity can not be realized.

\section{Online and Offline Reference Works}

Lancaster (1982) forecasts that by 1990 " 25 percent of existing reference books will only be available in electronic form. The 50 percent level will only occur after 2000." Some of the electronic versions may be sold outright just as their inkprint versions are; others may be licensed or require access fees for consultation. Online reference works will certainly be of great value to science and technology but cannot be supposed to satisfy an undergraduate's enormous appetite and weak budget. It should not be supposed that existing inkprint reference works will be rendered obsolete at any level of instruction and research, even by 1995 . Many physical constants published in tables and handbooks do not change; books like Who Was Who and the major retrospective encyclopedias in the arts and the humanities will most certainly endure. Gale Research Company, a major publisher of inkprint reference works "doesn't foresee databases replacing reference books as a library research tool. ${ }^{\prime 34}$

\section{An Educator's Model of the Future}

Not everyone concurs with Gale Research Company's conservative views. The compact disk, which has already revolutionized the sound recording, is sure to have an impact on scholarship. Portions of the MARC database are already available on a compact digital disk. It is not beyond imagination to suggest that at least some reference works may be available in this new format within the next decade, a development that might offer relatively cheap offline access. Samuel L. Dunn, speaking before a 1983 meeting of the World Future Society, suggested that new technologies would permit the future university to combine a medieval style of individualized tutoring with instructional delivery via electronics. Here is how students will interact with the library according to Dunn's forecast:

Most students in tomorrow's university will have their own personal computers and will be able to access information banks with ease and skill. The personal computers will be linked to university-wide networks that will allow students to call up most library materials and view them from their dormitory rooms or homes. ${ }^{35}$

The realization of such a forecast is beset with enormous social, technical, and financial problems-the implications of copyright and user fees alone are staggering. The traditional structures and curric- 
ula of colleges and universities would need to be revolutionized and higher education is not notable for implementing revolutions. The forecast presupposes the existence of vast new infrastructures for financing, organizing, distributing, presenting, and maintaining huge data banks dynamically. It must also be presupposed that a good deal of retrospective material will already have been digitized. But Dunn does not consider how that effort might be financed, let alone accomplished on the technical side. Over the past half century the library community has lived through earlier visionary proposals where economic, technical, and ergonomic problems had not been thought through by enthusiasts, e.g., microforms, and most especially the ultrafiche. ${ }^{36}$

Numerous obstacles stand in the way of realizing Dunn's future soon. They include: (1) decreasing financial support for education, (2) uncompleted research work essential for the development of new access systems for huge, dynamic files, and (3) the difficulties inherent in the social engineering necessary to alter the structure of the academic world. It is safe to say that his futuristic environment will not be created within the ten-year period encompassed by the present report. Even Dunn, in his forecast, suggests that it may take ten to twenty years to transform the university's curriculum from its three hundred years of discipline-centered traditions into something new. It has taken nearly fifteen years of laborious and difficult work to bring bibliographic networks and utilities to the point where they can deliver citations effectively, and that same amount of time before the widespread acceptance of the long-promoted idea that online public access catalogs would supersede the card catalog. Even though technology always accelerates in its development and time occasionally seems to telescope backwards, the delivery of full text is a problem that is one or two orders of magnitude more complex than the delivery of citations, and systems to accomplish it will not evolve overnight. Nor will faculty and librarians develop an overnight readiness either to work with such systems or to accept new structures in place of those that have developed over centuries. It will probably take at least one generation to get the process starteduntil those children now growing up with microcomputers reach academic maturity.

\section{Materials Delivery}

A recent summary of a CLRcommissioned report on document delivery contains some disturbing items:

- rapid turnaround "does not appear to be a high priority concern of the library profession as a whole, but rather of a limited number of concerned librarians who are assessing the future of libraries";

- there is "no significant shift away from present delivery patterns";

- "electronic technologies do not as yet play a major role in document delivery";

- none of the libraries investigated had studied document delivery time, but rather had "done an excellent job of convincing users to wait." ${ }^{\prime 37}$

This same issue of Information Hotline also reports that one in six U.S. households now uses microcomputers or has access to one at work or school. This figure may be exaggerated right now, but in a year or two one might expect an even lower ratio.

Easy access to microcomputers along with ACRL's commitment to "encourage innovation in academic and research library services" combine to justify probing this alleged lack of interest in rapid delivery. Long delay in consulting distant materials not only stifles research, but also weakens bibliographic instruction programs and damages related efforts to raise the quality of library service. The coming impact of electronic document ordering systems has already been mentioned. Although Aveney has suggested that "the disposable book [one that is printed on demand, at home or in the office] promises to cause the most significant changes in library organization, "that possibility is not immediate and cannot be given serious consideration at this time. ${ }^{38}$

\section{Computer Center/Library Relationship}

Those who have criticized library 
schools for adding the word "information" to their names may not have noticed the campus computer centers transforming themselves into the campus "information processing centers." It is now commonplace in a number of academic institutions for one officer to be responsible for all types of information services and facilities; the oldest and most notable instance is Columbia University where the library director has the title vice president for Library and Information Services.

Libraries and computer centers have long been in competition for the same dollars. Technology has advanced to the point where it is obvious that the two agencies represent different faces of the same coin. The library and its inkprint system have no monopoly on recorded knowledge; and given the libraries' huge and varied national bibliographic utilities and consortia, the computer center has no monopoly on CPU cycles. The challenge is to get them together and put an end to the bitter political battles that are waged for limited funds. An unfortunate result of this infighting is that it can pit scientists and humanists against each other, further polarizing the "two cultures."

Bringing the two major information forces together on one campus is no easy task: the head of a computer center is sometimes excessively hardware-focused, while the chief librarian is overly beset with problems of personnel, budget, and the always unreasonable demands of students and faculty for more materials, more hours, more study space. The ACRL community cannot take the risk that the two major information forces in academe might forever diverge. Indeed, the convergent character of the new communication, recording, storage, access, and retrieval technologies themselves ought to be exploited to meld these two complementary interests. Here is a good opportunity to halt Thompson's 'end of libraries" - a union of the major information processing forces on campus can forge a combined institution capable of services neither could hope to provide effectively on its own.

D. Kaye Gapen, director of libraries at the University of Wisconsin, speaking at the Third ACRL National Conference, called for librarians to "have the closest possible relationships with their computer centers." ${ }^{39}$ This excellent suggestion might be extended even further: if wasteful and destructive rivalry is not to occur, there must be administrative liaison at the highest levels. Academic officers responsible for instruction and research need to appreciate the fundamental unity of interest among these two complementary powers that, other than faculty themselves, must be among the most potent forces in any educational institution.

Though one sees an occasional report or article in the literature, there is very little to suggest that this bringing together is being addressed at the right levels and on the necessary scale. This is an opportunity for ACRL to establish linkages with appropriate organizations, such as the Association of American Universities (AAU), the National Association of College and University Business Officers (NACUBO), and similar associations representing the chief academic officers, computer center directors, and the planning officers of colleges and universities. There will be overlap here-and opportunity for additional collaboration-with similar efforts undertaken by the Association of Research Libraries.

\section{The Durable Library}

As indicated earlier in this paper, whatever the technical advances, some kind of institution will be needed to support the academic world, regardless of the form in which information is recorded and distributed. No one professor, scholar, researcher, student, or librarian can possibly have at his or her command the entire universe of recorded knowledge; unlimited access could not be afforded with conventional methods and materials and, $a$ fortiori, cannot be provided with new media. Technology may be able to give students and faculty members ever more powerful microcomputers, devices that come close to "mainframes" - but such devices cannot give to students and faculty what is known as the academic library. No for-profit organization can be counted upon to support the full range of 
materials essential for instruction and research.

Over the millennia the library has already experienced generations of changing media and has survived as an essential social institution. By whatever name it is designated, that institution, that infrastructure, will still be a library. And that infrastructure will still need librarians as intermediaries, teachers, consultants, ad- visers, and interpreters. As a matter of fact, the development of the so-called electronic library in higher education will impose even greater demands on academic librarians for, the less visible the medium, the greater the need for the intermediary. It is this message that ACRL should communicate to the academic world, especially to academic planning officers.

\section{REFERENCES AND NOTES}

1. Using the $1983 / 84$ ALA Handbook of Organization, the author informally surveyed thirty-five key ACRL leaders in the U.S. and Canada to obtain their views on many of the topics covered in this paper.

2. Blaise Cronin, "Adaption, Extinction or Genetic Drift?" ASLIB Proceedings 35:278-89 (June/July 1983), p. 279.

3. For excellent presentations distinguishing the sometimes confounded terms information, data, and knowledge, see Abraham Kaplan, "The Age of the Symbol-A Philosophy of Library Education," Library Quarterly 34:295-304 (Oct. 1964), and Joseph Z. Nitecki, "Old Ghost in a New Body: Some Misconceptions about Information-Knowledge Relations and the Role of Computers in Academic Libraries," Research Strategies 1:148-54 (Fall 1983).

4. The business community does not labor under this difficulty; there is a National Secretaries' Week, and business people don't confuse office equipment or hardware with the personnel who make the office function.

5. The American Council of Learned Societies currently has a membership of forty-three organizations, chiefly in the arts and humanities.

6. In the UK, the Standing Conference of National and University Libraries (SCONUL) has developed programs of bibliographic instruction for use in British academic libraries; some ACRL liaison with SCONUL may be appropriate.

7. Shirley Havens, "Academic Libraries: Myths and Realities," Library Journal 109:1419 ff. (Aug. 1984).

8. Millicent Abell and Jacqueline M. Coolman, "Professionalism and Productivity: Keys to the Future of Academic Library and Information Services," in Priorities for Academic Libraries, eds. Thomas Galvin and Beverly Lynch (San Francisco: Jossey-Bass, 1982), p.71-87. See esp. p.86.

9. Patricia Battin, "The Library: Center of the Restructured University," College \& Research Libraries 45:170-76 (May 1984).

10. In academic institutions service pins and certificates are clearly not workable and, in fact, can be counterproductive; both professional and classified employees often find such "awards" insulting and condescending, perceiving them as military, industrial, or pro forma in character.

11. James D. Koerner, The Present and the Future in Educational Technology (An occasional paper from the Alfred P. Sloan Foundation, New York, 1977) See esp. p.31.

12. Mark R. Yerburgh, "Some Unguarded Thoughts on Academic Librarianship: Vision vs Reality," CLIC Quarterly 2:11-19 (Dec. 1983). See esp. p.13.

13. Maurice B. Line cites as examples librarians "who say proudly, 'I am a cataloger' or 'I am an accessioner,' as if they were some special blood-group which was incompatible with others." (See p. 156 of Maurice B. Line, "The Functions of the University Library," in University and Research Library Studies, ed. W. L. Saunders, Oxford: Pergamon, 1968), p.148-58.

14. Thomas G. English, "Librarian Status in Eighty-nine U.S. Academic Institutions of the Association of Research Libraries, 1982," College \& Research Libraries 44:199-222 (May 1983). See esp. p.199, 207.

15. "Administrators' Views of Library Personnel Status," College \& Research Libraries 45:189-95 (May 1984). See esp. p.195.

16. Virgil Massman, Faculty' Status for Librarians (Metuchen, N.J.: Scarecrow, 1972), See esp. p.43.

17. Whether the "manufacturing" they do is industrial or bibliographic may not matter; if librarians' activity is perceived as having a manufacturing, custodial, or maintenance aspect, it probably will 
continue to be identified by faculty with low-status "housekeeping." In this sense, one can agree with advertising executives who claim that truth is irrelevant, that "perception is fact."

18. Academic librarians will want to observe carefully the library economics research seminars sponsored by the Council on Library Resources. These studies are currently focusing on the large research library but may ultimately have a bearing on systems of cost allocation for other types of academic libraries.

19. Maurice B. Line, "Some Possible Future Effects of Information Technology," IFLA Journal 10:57-62 (1984). See esp. p.58.

20. John F. Stirling, "Technological Developments in Information Transfer: Some Implications for Academic Libraries," Journal of Librarianship 14:235-46 (Oct. 1982). See esp. p. 244-45.

21. Herbert S. White, "Growing User Information Dependence and Its Impact on the Library and Information Service Fields, Journal of Library \& Information Science 9:1-18 (Apr. 1983). See esp. p.7.

22. NFAIS Press Release, Aug. 1984.

23. James Thompson, The End of Libraries (London: Bingley, 1982).

24. Maurice B. Line, "Ignoring the User: How, When, and Why," in The Nationwide Provision and Use of Information, Proceedings of the ASLIB/IIS/LA Joint Conference, Sheffield, 15-19 September 1980 (London: Library Association, 1981); p.80-88.

25. Thompson, The End of Libraries, p. 26.

26. The new technologies of teletext and videotex have been criticized as potential failures because their promoters have not understood the organizational aspects of information. A cursory examination of books and articles on these systems shows that many of their enthusiasts naively suppose that information is "self-organizing," an assumption that not even the greenest librarian would make.

27. F. Wilfrid Lancaster, "The Future of the Library in an Age of Telecommunications," in Changing Information Concepts and Technologies (White Plains, N.Y.: Knowledge Industry, 1982), p.159.

28. S. D. Neil, Canadian Libraries in 2010 (Vancouver, B.C.: Parabola, 1980), p.32.

29. Maurice J. Freedman is unwilling to bury technical services; he believes the future of automated technical services is a "rosy one." See Maurice J. Freedman, "Automation and the Future of Technical Services," Library Journal 109:1197-1203 (June 15, 1984).

30. Henriette D. Avram, "Barriers: Facing the Problems" (Prepared for the Association of Research Libraries Program on Bibliographic Control, Chapel Hill, N.C., Oct. 20, 1983. Typescript), p.6.

31. Motorola now produces a wireless terminal that fits into a briefcase-possibly a forerunner of a portable search terminal that students and faculty can use in the stacks, or anywhere (via cellular radio networks), to consult current and retrospective bibliographic files.

32. Edward A. Feigenbaum and Pamela McCorduck, The Fifth Generation: Artificial Intelligence and Japan's Computer Challenge to the World (Reading, Mass.: Addison-Wesley, 1983), p.88-89, 227-29.

33. Douglas R. Hofstadter, "Artificial Intelligence: Subcognition as Computation," in The Study of Information: Interdisciplinary Messages, editors Fritz Machlup and Una Mansfield, (New York: Wiley, 1983), p.271.

34. Ann Brewer, "Book or Data Bases in the 21st Century?" in Information and Special Libraries in 2009: Informed Speculations, eds. Judy Genesen and David E. King (Chicago: Special Libraries Assn., Illinois Chapter, 1984), see esp. p.4.

35. Samuel L. Dunn, "The Changing University: Survival in the Information Society," The Futurist 17:55-60 (Aug. 1983).

36. For an excellent analysis of how the several ultrafiche programs went awry, see Mark Yerburgh and Rhoda Yerburgh, "Where Have All the Ultras Gone? The Rise and Demise of the Ultrafiche Library Collection, 1968-1973," Microform Review 13:254-61 (Fall 1984).

37. "How Libraries Obtain Materials for Their Users," Information Hotline 15:1, 17 (Apr. 1984).

38. Brian Aveney, "Electronic Publishing and Library Technical Services," Library Resources \& Technical Services 28:68-75 (Jan./Mar. 1984), p.71.

39. D. Kaye Gapen, "Myths and Realities: University Libraries," in Academic Libraries, Myths and Realities (Proceedings of the Third National Conference of the ACRL, Chicago, 1984). See esp. p.9. 